\title{
LA ARQUEOLOGÍA COMO CIENCIA DEL ESPÍRITU: RELACIONES \\ ENTRE LA ARQUEOLOGÍA, LA HERMENÉUTICA FILOSÓFICA Y LAS CONSECUENCIAS PRÁCTICAS DE LAS INTERPRETACIONES
}

\author{
José María Vaquer ${ }^{1}$
}

\section{* Introducción}

Resumen

En este trabajo relaciono la hermenéutica filosófica, en particular las propuestas de Heidegger y Gadamer, con la arqueología contextual de Hodder en su vertiente inicial y en sus últimos trabajos. El objetivo es considerar la adecuación entre ambos y en qué medida la arqueología contextual toma las propuestas de la hermenéutica filosófica. En una primera instancia, sostengo que el proyecto de Hodder toma bastantes elementos de esta última, aunque pretende retener cierta objetividad en las interpretaciones, lo que no se condice con el marco teórico metodológico de la hermenéutica. En una segunda instancia, Hodder se aleja de este proyecto hacia una perspectiva más simétrica que produce un "ocultamiento" del intérprete. En la sección final evalúo ambas propuestas en función de las consecuencias prácticas de las mismas en el presente. Argumento que la hermenéutica es un método útil para lograr una arqueología relacional crítica que mitigue la violencia epistémica, incluyendo dialógicamente otras epistemes en las interpretaciones del pasado.

Palabras claves: hermenéutica - arqueología contextual - enredo arqueología relacional.

Abstract

In this paper I relate Philosophical Hermeneutics, particularly Heidegger and Gadamer's version with Hodder's Contextual Archaeology in its initial phase and in his latest work. The goal is to consider the adjustment between both, and the degree to which Contextual Archaeology takes the proposals of Philosophical Hermeneutics. In its first stage, I argue that Hodder's project takes several key elements from Hermeneutics, although he pretends to retain a degree of objectivity in interpretations. This doesn't fit with the Hermeneutics theoretical-methodological framework. In a second stage, Hodder moves away from this project to a more symmetrical stance that produces a "concealment" of the interpreter. In the final section, I evaluate both Hodder's proposals regarding their practical consequences in the present, and finally I argue that Hermeneutics is a useful method to achieve a Relational Archaeology that mitigates epistemic violence including a dialog between other epistemes in past interpretations.

Key words: Hermeneutics - Contextual Archaeology - Entanglement Relational Archaeology.

Recibido: Octubre 2014. Aceptado: Octubre 2015
“Contra el positivismo, que se detiene en los fenómenos: «sólo hay hechos» - yo diría: no, precisamente no hay hechos, sino sólo interpretaciones". Friedrich Nietzsche, Fragmentos Póstumos 7 (60).

Las modas teóricas se suceden. Debido a la posición marginal y principalmente consumista de la teoría arqueológica que ocupamos en la academia mundial, en muchos casos adoptamos marcos teóricos importados sin preguntarnos por su origen y sus consecuencias para nuestra práctica científica. Ante esta situación, podemos tomar al menos dos posiciones: o nos detenemos a interpretar los supuestos de los marcos teóricos que utilizamos y los adaptamos a nuestras realidades, o comenzamos a elaborar un corpus teórico que surja a partir de nuestras condiciones sociales. Ambas opciones no son excluyentes e idealmente la primera de ellas podría ser considerada un paso hacia la segunda.

Este trabajo consiste en un intento de aplicar la primera opción, es decir, realizar una deconstrucción crítica de la relación entre arqueología y hermenéutica. Ya desde sus orígenes, la arqueología post procesual se presentó a sí misma como arqueología hermenéutica (Hodder 1986, 1991). De hecho, a partir de las críticas realizadas por Hodder y otros a la arqueología procesual, surgió una diversidad de enfoques que fueron denominados "post procesuales", pero que difieren bastante entre sí. En otro trabajo (Vaquer 2013b) propuse dejar de lado la categoría de post procesual y referirme a estos enfoques bajo el término "arqueología hermenéutica", ya que el enfoque hermenéutico es lo que tienen en común todas las propuestas. Ahora bien, iqué significa un enfoque hermenéutico?

1 Consejo Nacional de Investigaciones Científicas y Técnicas. Instituto de Arqueología, Facultad de Filosofía y Letras, Universidad de Buenos Aires. 25 de Mayo 217, 3er Piso. CP (1002ABE), Buenos Aires, ARGENTINA. Email: jmvaquer@yahoo.com 
Para responder a la pregunta anterior, es necesario relacionar la arqueología con la filosofía, en particular con la filosofía continental europea. La hermenéutica filosófica fue una de las corrientes más importantes en el siglo XX a partir de su elaboración por parte de Martin Heidegger (1889-1976) y Hans-Georg Gadamer (19002002). Johnsen y Olsen (1992) proponen un recorrido similar, aunque su objetivo principal es criticar la postura de Hodder por ignorar la hermenéutica de Gadamer en su versión de la arqueología. Si bien presentan de manera general la hermenéutica, no profundizan las relaciones entre esta y la arqueología más allá de su postura crítica. Por lo tanto, considero necesario ampliar la propuesta de estos autores y explicitar cuáles son las consecuencias de adoptar un marco hermenéutico para nuestras interpretaciones del pasado.

En relación con el último punto, explicitar la lógica de la hermenéutica como marco interpretativo permite considerar dos puntos de suma importancia: el primero de ellos, ubicar a la arqueología dentro de la tradición de las ciencias humanas (o "ciencias del espíritu", Geisteswissenschaften en alemán) basadas en la interpretación; y el segundo, considerar las consecuencias prácticas y éticas de las interpretaciones arqueológicas a partir de las nociones de "situación hermenéutica" y de "conciencia de la historia efectual", elaboradas por Gadamer (2003). En este sentido, las interpretaciones siempre se realizan a partir de intereses presentes, por lo que tienen un impacto en el presente a partir de la confrontación con la tradición. Al formar parte de la tradición que se interpreta, los investigadores nunca logramos un conocimiento "objetivo" del pasado. En consecuencia, la hermenéutica permite preguntarnos por los intereses detrás de las interpretaciones, y de esta manera realizar una práctica crítica.

Para realizar este recorrido, propongo aplicar un enfoque hermenéutico. En estos términos, el objetivo del trabajo es una confrontación entre dos tradiciones: la filosofía hermenéutica y la arqueología hermenéutica para considerar los puntos de confluencia y divergencia entre ambas. Con respecto a la primera, presento una breve caracterización de la hermenéutica filosófica para centrarme luego en dos autores que son centrales y realizan un "giro ontológico" (Grondin 1999; Ricoeur 2002) dentro de la disciplina: Martin Heidegger y Hans-Georg
Gadamer. El segundo fue discípulo del primero, y su consideración de la hermenéutica puede entenderse como la aplicación de la estructura originaria de la comprensión del Dasein a la historia, tal cual fue expuesta por Heidegger en Sery tiempo y sus obras anteriores.

Una vez definidas las notas distintivas de la hermenéutica de Heidegger y Gadamer, hago un recorrido por las principales corrientes de la arqueología hermenéutica para considerar de qué manera aplican o no los principios hermenéuticos. Me centro particularmente en la arqueología contextual de Hodder (1986, 1991), con su noción de cultura material y la analogía con el texto, y cómo modificó su postura en sus últimos trabajos (Hodder 2012), tratando de determinar si continúa o no con su postura hermenéutica inicial. El objetivo es evaluar la adecuación entre las propuestas de la arqueología hermenéutica y la hermenéutica filosófica.

En la sección final del trabajo considero las consecuencias prácticas y éticas de la arqueología hermenéutica, y sugiero que un marco de estas características permite realizar el programa de una arqueología comprometida socialmente, propuesto por Shanks y Tilley (1987). El argumento que sostengo es que una arqueología hermenéutica necesariamente debe tener en cuenta los intereses y prejuicios de los intérpretes que conforman la "situación hermenéutica" de toda interpretación. A partir de una explicitación y análisis de los intereses de los diferentes agentes involucrados en las interpretaciones de la cultura material, es posible construir una arqueología dialógica que cuestione las pretensiones de verdad de la ciencia, incorporando las interpretaciones del pasado de los grupos locales. Por lo tanto, la arqueología hermenéutica no es un "todo vale" posmoderno, sino que puede ser un marco interpretativo para un arqueología comprometida socialmente, en contra de las críticas que le hicieron algunos arqueólogos marxistas (por ejemplo, Aguilar Díaz y Tantaleán 2008).

* Primera parte: la hermenéutica filosófica

\section{La hermenéutica filosófica: sus orígenes. Ciencias naturales y ciencias del espíritu}

La siguiente reconstrucción de la hermenéutica temprana se encuentra basada en los trabajos de Grondin (1999, 
2008) y de Ricoeur (2002, 2003). "Hermenéutica"

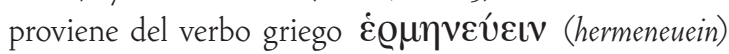
y puede significar: expresar (afirmar, hablar), explicar (interpretar, aclarar) y traducir (trasladar). Se refiere a un movimiento del espíritu que apunta a la comprensión, uno que se dirige hacia afuera (expresar) y otro hacia adentro (interpretar). El interpretar es una búsqueda del sentido interior detrás de lo expresado, en tanto que el expresar da a conocer algo interior. En el caso de los griegos, esta operación no era problemática, ya que consideraban que había una relación directa entre el pensamiento y la palabra.

Si bien el concepto de hermenéutica como interpretación estuvo presente a lo largo de toda la historia de la filosofía, fue recién en el siglo XVII que recibe sus credenciales en tanto doctrina de la comprensión de textos. En este momento, se reconocen tres ramas: la hermenéutica teológica o sacra, la hermenéutica filosófica o profana y la hermenéutica jurídica. A partir del siglo XVIII, con el romanticismo alemán se plantea la posibilidad de una hermenéutica general como arte de la comprensión basado en principios más rigurosos.

La hermenéutica romántica tiene su antecedente en la Crítica de la razón pura de Kant. En esta obra, el filósofo de Königsberg limita el entendimiento al ámbito de los fenómenos, por lo que cuestiona los principios del racionalismo que postulaba un acceso directo y no problemático de la razón a la realidad. Kant propone que "pensar un objeto, y conocer un objeto no es, pues, lo mismo" (Kant 2009: 213, énfasis en el original), ya que el conocimiento se produce en el ámbito de los fenómenos. En consecuencia, la "cosa en sí" resulta incognoscible. Lo que conocemos es resultado de los esquemas a priori de nuestro entendimiento, que operan con ocasión de la sensibilidad, por lo que el acceso al mundo se efectúa por medio de una visión subjetiva. A partir de la crítica kantiana, la reflexión filosófica parte desde el sujeto y las condiciones de posibilidad del conocimiento.

Friedrich Schleiermacher (1768-1834) propone que el principio de la hermenéutica es que todo acto de comprender es la inversión del acto de hablar, en tanto debe llegar a la conciencia el pensamiento que subyace a lo que se dice. La tarea fundamental del comprender, entonces, es la reducción de la expresión al "querer decir" que se encuentra detrás. Lo que se trata de comprender es el sentido de algo que se dice, lo otro o lo pensado que se manifiesta en la expresión. En consecuencia, el entender tiene por objeto el lenguaje. Schleiermacher propone dos vertientes de la hermenéutica: una gramática y otra técnica. La gramática contempla el lenguaje desde la totalidad de su uso lingüístico, mientras que la técnica y psicológica, como la expresión de algo interior.

Para Schleiermacher, el malentendido es el hecho fundamental de la interpretación, ya que el no entender nunca se puede disipar del todo. En consecuencia, y de acuerdo con la crítica kantiana, la operación básica de la hermenéutica o la comprensión es una reconstrucción. Existe un principio de la mejor comprensión o comprensión ideal como meta inalcanzable del entender. Otra nota del pensamiento de este autor es que la hermenéutica se encuentra subordinada a la dialéctica, por lo que la interpretación involucra un diálogo: interpretar un texto significa entrar en diálogo con él, plantearle preguntas y dejar que él también nos plantee preguntas. En este diálogo se constituye el círculo hermenéutico, entendido como la relación entre el todo y las partes. En el aspecto gramatical, el todo es el género literario desde el cual se puede iluminar el texto singular que surge de él, mientras que en la vertiente psicológica o subjetiva hay que considerar el pasaje, la obra como un acto de su autor y explicarlo desde la totalidad de su vida.

Otra corriente que se preocupó por llevar a la hermenéutica al status de metodología fue el historicismo alemán del siglo XIX. En esta corriente se propuso que la hermenéutica sería el método de las ciencias del espíritu, en general, y de la historia, en particular.

Johann Droysen (1808-1886), en un intento de dar una legitimación metodológica a la historia, propone que la comprensión debería ser el concepto metodológico central de la misma. La finalidad de la historia es justificar su propio sentido y el método propio a los estudios históricos. Para Droysen, el acontecer del mundo se encuentra dividido en dos conceptos guía que ya fueron reconocidos por Kant como las intuiciones puras de la sensibilidad: el espacio y el tiempo. Al primero corresponde la naturaleza (la quietud) y al segundo la historia (lo cambiante). A su vez, las dos dimensiones se relacionan con dos dimensiones del ser humano, el espíritu y la sensibilidad. En 
consecuencia, existen dos maneras de considerar lo que es: desde las ciencias de la naturaleza y desde las ciencias del espíritu.

Mientras que el método de la ciencia natural consiste en la búsqueda de leyes normativas para los fenómenos observados, la esencia de la ciencia histórica consiste en comprender mediante la investigación. Para Droysen, comprender significa reconducir las expresiones a lo que se quiso expresar con ellas. Lo que se trata de comprender no es el pasado mismo, puesto que ya no está presente, sino lo que aún se conserva de él en los materiales y las fuentes existentes. La comprensión de lo histórico se dirige a los restos del pasado que se han conservado hasta el presente. La comprensión es el reconocer de algo conocido, es decir, el penetrar en lo conservado por la tradición que todavía podemos alcanzar para reconstruir, a partir de ello, el espíritu del pasado. Cuando el historiador se sitúa e investiga detrás y en el interior de las manifestaciones históricas, pretende reconstruir lo singular a partir del todo que emanan, y a la inversa, el todo a partir de lo singular en el que se expresa utilizando el círculo hermenéutico.

Otro autor importante dentro del historicismo alemán fue Wilhelm Dilthey (1833-1911). Este investigador propone, en un tenor kantiano, una "crítica de la razón histórica" que legitime la categoría científica de las ciencias del espíritu. Para ello, intenta buscar una fundamentación de las bases gnoseológicas de validez general de las ciencias del espíritu. El anclaje es en la experiencia interior, los "hechos de conciencia" o vivencias. La experiencia encuentra su coherencia y validez en el "a priori" estructurante de nuestra conciencia. En consecuencia, los hechos de conciencia representan las condiciones objetivas de validez de las ciencias del espíritu en la experiencia interior. Se basa en el "principio de fenomenalidad" que postula que toda la realidad (todos los hechos externos, tanto objetos como personas) está bajo las condiciones de la conciencia. Por lo tanto, Dilthey propone una psicología explicativa que busque la explicación causal de los fenómenos psíquicos, reduciendo la vida anímica a un número limitado de elementos definidos, y una psicología comprensiva que parte del todo del contexto vital tal como se da en la vivencia. El objetivo es lograr una comprensión de la vida anímica en su coherencia estructural originaria. Basándose en la división entre las ciencias de la naturaleza y las ciencias del espíritu propuesta por Droysen, Dilthey sostiene que explicamos la naturaleza y comprendemos la vida anímica.

En la aprehensión directa de las vivencias interiores viene dada una estructura firme de manera inmediata y objetiva. El principio de las vivencias sostiene que todo lo que existe para nosotros sólo existe en tanto algo dado en el presente. En este marco, el concepto de comprensión funciona como puente entre las vivencias y las ciencias del espíritu. La comprensión consiste en remontarse desde lo expresado al interior, a la autorreflexión que se da a conocer en la expresión. Toda expresión surge de un reconsiderar consigo mismo que intenta vivenciar retrospectivamente lo que se propone comprender, estableciendo una relación entre vida, expresión y comprensión. La exégesis o interpretación debe consistir en una comprensión entrenada como arte de manifestaciones vitales fijadas de manera permanente. La hermenéutica sería una respuesta a la pregunta por el conocimiento científico de lo individual, o sea, por las reglas de validez general para asegurar la comprensión de la contingencia subjetiva.

Como síntesis de los orígenes de la hermenéutica, podemos destacar que esta disciplina fue propuesta como marco de validez científica de las ciencias del espíritu. Las ciencias se dividen de acuerdo a sus objetos, y sus objetos requieren aparatos metodológicos particulares. Esta dicotomía queda plasmada en la distinción entre la explicación y la comprensión. Según Ricoeur:

"La explicación encuentra su campo paradigmático de aplicación en las ciencias naturales. Cuando hay hechos externos que observar, hipótesis que someter a la verificación empírica, leyes generales para cubrir tales hechos, teorías para abarcar las leyes dispersas en una totalidad sistemática y una subordinación de las generalizaciones empíricas a los procedimientos hipotéticos - deductivos, entonces podemos decir que 'explicamos'. Yel correlato apropiado de la explicación es la naturaleza, entendida como el horizonte común de hechos, leyes y teorías, hipótesis, verificaciones y deducciones [...] En contraste, la comprensión encuentra su campo originario de aplicación en las ciencias humanas, en las que la ciencia tiene que ver con la experiencia de otros sujetos u otras mentes semejantes a las nuestras. Depende de la significatividad de formas de expresión tales como los signos $f_{i-}$ sonómicos, gestuales, vocales o escritos, así como de documentos y monumentos que comparten con la escritura las características 
generales de la inscripción" (2003: 84-85).

A su vez, la comprensión depende de un círculo hermenéutico, donde se interpreta la parte a partir del todo, y el todo a su vez desde las partes. La comprensión toma la forma de un espiral, donde se van poniendo en juego cada vez más niveles de interpretación. Otro punto a destacar es la vocación dialógica de la hermenéutica, ya que la comprensión implica un diálogo con los textos, haciéndoles preguntas y dejando que pregunten a su vez. Esto último es posible porque también se reconoce que la tarea de interpretación se realiza en el presente, con preguntas que se relacionan con la situación presente del intérprete.

\section{El giro ontológico en la hermenéutica: Heidegger y Gadamer}

Tanto Grondin (1999) como Ricoeur (2002) adjudican a Martin Heidegger y a Hans-Georg Gadamer un "giro ontológico" en la hermenéutica filosófica. Esto implica que el comprender no va a ser más una cuestión meramente metodológica que justifica a las ciencias del espíritu, sino que se trata de una estructura ontológica del existente humano. Heidegger se encarga de caracterizar al comprender como existenciario, mientras que Gadamer lo aplica a la historia. Voy a comenzar por el primero.

Martin Heidegger (1889-1976) se mostró preocupado, desde sus trabajos anteriores a Ser y tiempo (1927), por una redefinición de la tarea de la filosofía. En La idea de la filosofía y el problema de la concepción del mundo, un curso que dictó en el semestre de posguerra de 1919 (conocido como KNS por Kriegsnotsemester) propone que la filosofía debe ser una ciencia originaria circular, con presupuestos y fundamentos que se dan a sí mismos. Para ello, la filosofía como ciencia originaria se debe focalizar en la vida, en el sentido de las vivencias. Una de las vivencias que analiza en el curso es la vivencia del mundo circundante como una experiencia significativa. En este sentido, propone que la vivencia del mundo circundante se da significativamente de manera originaria, sin la mediación del intelecto. En consecuencia, las vivencias son un ámbito originario que posee significatividad de manera atemática y pre-reflexiva (Heidegger 2005).

Otro trabajo significativo en la definición de la hermenéutica son las Interpretaciones fenomenológicas sobre Aris- tóteles de 1922. Esta obra fue un informe que Heidegger le presentó a Paul Natorp para optar por una vacante de profesor titular en la Universidad de Friburgo. En ella, introduce el concepto de "situación hermenéutica":

"El contenido real de toda interpretación, es decir, el objeto temático en la manera en que ya ha sido interpretado, sólo se logra mostrar directa y adecuadamente cuando la correspondiente situación hermenéutica de la que depende toda interpretación resulta accesible de manera suficientemente clara. Toda interpretación se despliega, en función de su ámbito de realidad y de su pretensión cognitiva, en el marco de las siguientes coordenadas: 1) un punto de mira, más o menos expresamente apropiado y fijado; 2) una subsiguiente dirección de la mirada, en la que se determina el 'como-algo' según el cual se debe precomprender el objeto de la interpretación y el 'hacia-donde' debe ser interpretado ese mismo objeto; 3) un horizonte de la mirada delimitado por el punto de mira y por la dirección de la mirada, en cuyo interior se mueve la correspondiente pretensión de objetividad de toda interpretación" (Heidegger 2002: 28-29, énfasis en el original).

Y a continuación:

"La situación de la interpretación, en cuanto apropiación comprensiva del pasado, es siempre la situación de un presente viviente. La inteligibilidad de la historia misma, a modo de pasado reapropiado en la comprensión, aumenta de manera decisiva en función del grado de originariedad con que se determina y elabora la situación hermenéutica. El pasado sólo se manifiesta con arreglo a la resolución y a la capacidad de apertura de la que dispone el presente" (Heidegger 2002: 29, énfasis añadido).

La situación hermenéutica está conformada por tres elementos: un punto de mira, una dirección de la mirada y un horizonte de la mirada. Esta estructura triple es reelaborada en el \$32 de Ser tiempo como "triple estructura del Vor". Esta estructura se compone de un "tener previo" (Vorhabe), un "ver previo" (Vorsicht) y un "concebir previo" (Vorgriff). El "tener previo" implica la posesión de un horizonte de referencia previo ya comprendido como trasfondo del ente a interpretar. Es el contexto precomprendido sobre el que se destaca el ente. El "ver previo" tiene que ver con las posibilidades de interpretación desde un punto de vista o perspectiva con intereses concomitantes. El "concebir previo" refiere a la sedimentación 
de interpretaciones pasadas que determina la interpretación presente. En síntesis, una interpretación siempre depende de un horizonte previo sobre el cual destaca el ente a interpretar, de la perspectiva e intereses del intérprete y las interpretaciones pasadas sedimentadas (Heidegger 2012).

Como mencioné anteriormente, Hans-Georg Gadamer (1900-2002) fue discípulo de Heidegger, y aplicó el comprender en tanto existenciario a la historia. Su punto de partida es la estructura ontológica de la circularidad hermenéutica. Esta conforma un círculo universal, ya que todo entender está determinado por una motivación o prejuicio. Los prejuicios -o comprensión previatienen el valor de "condiciones trascendentales del entender". Nuestra historicidad no es una limitación, sino un principio del entender. En este sentido, propone un reconocimiento y elaboración interpretadora de los prejuicios en un entender críticamente reflexivo que procure no simplemente llevar a cabo sus anticipaciones, sino hacerlas conscientes para controlarlas y obtener así la comprensión adecuada desde las cosas (Gadamer 2003).

Uno de los conceptos centrales en Verdad y método I es el de "conciencia de la historia efectual". Implica que nuestra conciencia actual está marcada y constituida por una determinada historia de la trasmisión, es decir, fue "efectuada" por la historia. En consecuencia, hay una conciencia de este "estar efectuada" mismo. La misma historicidad se constituye en la situación hermenéutica. El entender o la aplicación no es, en primer lugar, el acto de un sujeto autónomo, sino un integrarse en el acontecer de la trasmisión donde pasado y presente se encuentran en una mediación constante. El mismo acto de la interpretación es parte de la efectuación de la historia, por lo que la relación que se constituye entre el intérprete y lo interpretado no es una relación de sujeto y objeto, ya que el sujeto se encuentra formando parte de la misma tradición que va a interpretar. En consecuencia, no existe una visión "objetiva" de la historia, porque la interpretación es siempre un efecto de la misma que incluye al intérprete.

Entender un texto del pasado significa traducirlo a nuestra situación y escuchar en él una respuesta elocuente a las preguntas de nuestra época. La verdad es considerada como develación del sentido que se produce en el curso de la aplicación dentro de la trasmisión histórica. El en- tender es siempre la continuación de un diálogo que ya había comenzado antes de nosotros.

La hermenéutica de la aplicación es una "dialéctica de preguntas y respuestas". Entender algo significa haber encontrado una respuesta a nuestras preguntas. Pero sólo son nuestras en la medida en que fueron recogidas y transformadas desde una tradición. Todo entender, especialmente en tanto entenderse a sí mismo, está motivado y movido por preguntas que determinan de antemano las perspectivas del entender. El entender es una realización histórico transmisora de la dialéctica de la pregunta y la respuesta.

Con respecto al círculo hermenéutico y el criterio de corrección del entender, Gadamer propone que:

"En este punto recordaremos la regla hermenéutica de comprender el todo desde lo individual y lo individual desde el todo [...] Aquí como allá subyace una relación circular. La anticipación de sentido que hace referencia al todo sólo llega a una comprensión explicita a través del hecho de que las partes que se determinan desde el todo determinan a su vez a este todo.

Este hecho nos es familiar por el aprendizaje de las lenguas antiguas. Aprendemos que es necesario "construir" una frase antes de intentar comprender el significado lingüistico de cada parte de dicha frase. Este proceso de construcción está sin embargo ya dirigido por una expectativa de sentido procedente del contexto de lo que le precedía. Por supuesto que esta expectativa habrá de corregirse si el texto lo exige. Esto significa entonces que la expectativa cambia y que el texto se recoge en la unidad de una referencia bajo una expectativa de sentido distinta. El movimiento de la comprensión va constantemente del todo a la parte y de ésta al todo. La tarea es ampliar la unidad del sentido comprendido en círculos concéntricos. El criterio para la corrección de la comprensión es siempre la congruencia de cada detalle con el todo. Cuando no hay tal congruencia, esto significa que la comprensión ha fracasado" (Gadamer 2003: 361).

Vemos, entonces, que Gadamer retoma los elementos fundantes de la hermenéutica pero desde una perspectiva ontológica, ya que el comprender (se) a sí mismo, y a la historia como tradición efectuada, es parte de nuestro ser en tanto Dasein. La perspectiva que nos ofrece es un círculo en el cual la parte incluye al todo y el todo a la parte, y es la coherencia entre ambas y las anticipaciones de sentido lo que proveen el criterio de validez de las in- 
terpretaciones. Un punto importante es que retoma el concepto heideggeriano de "situación hermenéutica" en tanto conjunto de prejuicios con los cuales nos acercamos a la interpretación de los fenómenos. Por lo tanto, toda interpretación se produce desde un lugar situado. A partir de esta premisa, propone que la hermenéutica es un diálogo donde, desde una situación hermenéutica particular, se establece un juego de preguntas y respuestas entre el pasado y el presente, pero siempre desde los intereses presentes.

\section{* Segunda parte: Una arqueología de la ARQUEOLOGÍA HERMENÉUTICA}

\section{La arqueología hermenéutica británica. La cultura material como texto}

Una de las rupturas que propone la arqueología hermenéutica con respecto a la arqueología procesual es que el paradigma positivista que emplea esta última no es suficiente para generar explicaciones relevantes sobre el pasado (Shanks y Tilley 1987). La relevancia es entendida en términos de los efectos presentes de las interpretaciones sobre el pasado y el rol causal de los agentes sociales en el cambio.

La arqueología procesual sostiene una posición epistemológica rupturista entre el pasado y el presente. El pasado, identificado con el "contexto sistémico" de Schiffer (1972) o el "sistema vivo" de Binford $(1988,1996)$ es algo objetivo, real, cuyos restos debe explicar el arqueólogo/a en un intento de devolver la dinámica al "sistema muerto", representado por el registro arqueológico. Para esta tarea es fundamental la separación objetiva entre los investigadores, sus intereses y las explicaciones sobre el pasado. La explicación es, de esta manera, objetiva y objetivante. El pasado es un objeto diferente del presente, que se puede explicar objetivamente eliminando cualquier sesgo por parte del intérprete.

Con respecto al sentido, también se produce una ruptura. Para la arqueología procesual, lo que explicamos es el sentido del sistema cuando estaba activo. El pasaje entre el contexto sistémico y el contexto arqueológico implica un vaciamiento de sentido, salvo por la operación de los procesos de formación del registro, que sirven como puente entre un estado del sistema y el otro.
Contra estos supuestos epistemológicos se erige la crítica de la arqueología hermenéutica. Por un lado, la vertiente crítica sostiene que el pasado es una narrativa que se realiza desde el presente, por lo que no existe un pasado "objetivo" fuera de nuestras interpretaciones del mismo. La arqueología es un discurso que se elabora desde el presente, con consecuencias políticas en el presente (Shanks y Tilley 1987). Por otro lado, Hodder (1986) critica que el énfasis de la arqueología procesual en los procesos ambientales como generadores del cambio social y explicación última de los mismos, deja de lado a la agencia humana, y sobre todo, a los significados simbólicos de la cultura material como parte de las explicaciones del cambio. En consecuencia, es necesario dejar de lado la epistemología positivista con su énfasis en las leyes cobertoras e introducir a los agentes humanos en las explicaciones sobre el pasado. Para ello, va a retomar los supuestos de la hermenéutica en tanto ciencia de la interpretación.

En Reading the past, Hodder (1986) propone que, ante cualquier pregunta sobre el pasado humano, intervienen marcos de significados. En consecuencia, la tarea de la arqueología es reconstruir los significados simbólicos del pasado, a partir del enfoque que denomina "arqueología contextual". El término "contexto" posee, para Hodder, varias acepciones en arqueología que tienen en común la conexión o el entrelace de las cosas en una situación particular o grupo de situaciones.

Define dos tipos de significados que pueden ser estudiados por los arqueólogos. Uno de ellos es el sistema de interrelaciones funcionales, y el otro, el contenido estructurado de ideas y símbolos. El primero de ellos involucra el ambiente físico y humano, los procesos depositacionales, la organización del trabajo, el tamaño de los asentamientos y los intercambios entre materia, energía e información. El significado de los objetos es dado en relación con las estructuras sociales y económicas. El segundo tipo de significado, el contenido de las ideas y los símbolos, se obtiene a través de hacer abstracción de las funciones simbólicas de los objetos para identificar el contenido significativo. Esto implica examinar la manera en la que las ideas denotadas por los símbolos materiales juegan un papel en la estructuración de la sociedad.

Para acceder al significado simbólico, Hodder (1986) propone que el registro arqueológico puede ser conside- 
rado como un texto a ser leído, por lo que iguala a la cultura material con un lenguaje. Una premisa que sostiene es que existen reglas muy simples en la base de todos los lenguajes, que operan en todos los tiempos y en todos los lugares: "Por supuesto que todos los lenguajes deben ser interpretados, $y$, por lo tanto, en un sentido, todos los actos del habla y los símbolos materiales son mudos, pero un símbolo material en su "texto" no es más o menos mudo que cualquier gruñido u otro sonido utilizado en el habla. Los artefactos nos hablan - el problema viene en la interpretación" (Hodder 1986: 126).

Sin embargo, reconoce que hay diferencias entre el lenguaje y la cultura material. Una de ellas es que no existen reglas gramáticas claras en la cultura material. Los símbolos materiales son a veces más ambiguos que los verbales, y lo que puede decirse con ellos es normalmente más simple. Debido a la duración de los símbolos materiales, también existe una restricción a la flexibilidad de los significados. En consecuencia, el lenguaje material es mucho más simple que el verbal y el escrito, y los texto materiales son más fáciles de descifrar que los documentos escritos en los cuales no conocemos el lenguaje.

Existe un "principio universal del significado" (Hodder 1986: 127) detrás de una serie de experiencias — cada evento particular tiene un significado que puede ser comprendido por todas las personas en todos los tiempos, a partir de un conjunto de asociaciones y contrastes - que son seguidos rutinariamente por todos en tanto actores sociales, y por los arqueólogos al interpretar el pasado².

Una aclaración es que los significados internos subjetivos que los arqueólogos pueden inferir no son "ideas" en la mente de las personas del pasado, sino que son conceptos públicos y sociales que son reproducidos en las prácticas de la vida cotidiana. Son visibilizados para los arqueólogos debido a las prácticas institucionalizadas de los grupos sociales, tienen una rutina que lleva a repeticiones y patrones. Segundo, el contexto de producción de la cultura material es más concreto que el del lenguaje y el habla. Los significados de la cultura material son

2 Aunque no es citado por Hodder, este principio que garantiza la posibilidad de la interpretación es el mismo que propone Dilthey respecto a la universalidad de las vivencias. influenciados por consideraciones tecnológicas, físicas y funcionales. Para Hodder (1986), la naturaleza concreta y parcialmente no cultural de esos factores permite que el texto material sea leído de manera más fácil que los signos arbitrarios del lenguaje. Los contextos materiales no solamente son abstractos y conceptuales, sino también pragmáticos y no arbitrarios. Para la cultura material, el contexto se encuentra conformado por la totalidad de las dimensiones de variación (temporales, espaciales, depositacionales y tipológicas) alrededor del objeto, que son necesarias para determinar su significado. Las dimensiones significativas de variación definen estructuras de significados.

Otra nota interesante es que Hodder (1986) propone que la explicación y la descripción son lo mismo. Las descripciones de contextos cada vez más amplios, como redes de asociaciones y contrastes, funcionan como explicaciones de los fenómenos. La arqueología contextual une explicaciones adecuadas con descripciones detalladas. Esto implica, a su vez, un movimiento desde los datos a las teorías y viceversa. No existe una independencia entre las teorías y los datos: ambos se encuentran mezclados en la interpretación. Para ello, toma la primera regla de la hermenéutica de Gadamer: debe entenderse la parte en términos del todo y el todo a partir de la parte. Como intérprete, se debe jugar entre las partes y el todo hasta alcanzar una armonía de los detalles con el todo. Esto implica alcanzar una comprensión de la situación. También propone una dialéctica de preguntas y respuestas que continua en un espiral sin fin, ya que cada respuesta crea nuevas preguntas, y tiene en cuenta los intereses del presente en la formulación de las preguntas. En este sentido, la noción de contexto que propone Hodder es similar al concepto de horizonte de Gadamer: "el intento de fusionarse con el otro [horizonte], mientras sea realizado de manera crítica y teniendo en cuenta las diferencias y los contextos, cambia nuestra experiencia y por lo tanto, cambia nuestra perspectiva. Como se mencionó, el círculo hermenéutico no es vicioso. Se mueve continuamente y dialécticamente en el proceso de preguntas y respuestas y en este movimiento, el pasado y el presente, el sujeto y el objeto son ambos fusionados y separados" (Hodder 1986: 152).

En otro trabajo, Hodder (1991) considera a la hermenéutica como un componente importante de una arqueología 
interpretativa o contextual que opera a partir de las relaciones parte-todo. Propone que este tipo de interpretación hermenéutica permite construir los datos en sus propios términos, utilizando los datos "desde dentro" en vez de subsumirlos en leyes generales o universales. Sin embargo, sostiene que un enfoque hermenéutico no es suficiente, ya que para superar las críticas al postestructuralismo es necesario dotar a las interpretaciones del pasado de un criterio de validez objetivo, y en consecuencia, externo. La posición interpretativa que propugna Hodder se basa en tres aspectos esenciales:

1) Una retención de la "objetividad" del pasado. Los datos se constituyen en una relación dialéctica.

2) Un componente hermenéutico interno, que consiste en entender el pasado en términos de la experiencia social de los actores.

3) Una consideración reflexiva de la construcción del conocimiento arqueológico.

Con respecto al primer punto, Hodder propone que el objeto del pasado y el sujeto del presente se constituyen dialécticamente. Las posiciones del intérprete y del pasado interpretado son superadas en círculos hermenéuticos cada vez más amplios. Existe una independencia de los restos materiales que debe ser confrontada con las suposiciones o prejuicios que conforman la tradición del intérprete: "Solamente podemos entender el pasado en sus propios términos si entendemos nuestro propio contexto en la dialéctica entre el pasado y el presente. El pasado solamente puede informar al presente a través de la tarea dual de entender el presente y el pasado como diferentes pero dependientes" (Hodder 1991: 13).

El segundo punto consiste en interpretar las estructuras públicas y sociales de significados mediante las cuales las personas dotan de sentido su mundo. Estos "reinos conceptuales de significados" son históricos y arbitrarios, pero pueden ser interpretados utilizando el enfoque hermenéutico de la parte y el todo, debido a que los significados fueron utilizados en la acción social y produjeron efectos repetidos que conforman patrones en la cultura material y en la organización espacial y temporal de las relaciones.

El tercer punto se relaciona con el aspecto auto-reflexivo de la escritura arqueológica. En este sentido, Hodder considera que la arqueología interpretativa se dedica a construir narrativas o contar historias. Sin embargo, se contradice cuando propone que "el arqueólogo debe retener la autoridad [sobre las interpretaciones] para determinar si una interpretación particular no encaja en los datos [...] y necesitan darse cuenta que se puede proveer a los grupos subordinados con los mecanismos (las posibilidades materiales y educacionales) para hacer frente al pasado en sus propias maneras" (Hodder 1991: 16).

En síntesis, para Hodder el enfoque hermenéutico permite realizar un balance entre la objetividad de la cultura material y la subjetividad de las interpretaciones internas. A su vez, también permite un acercamiento crítico a la arqueología como narrativa. Sin embargo, es notorio que en estos primeros trabajos, donde Hodder busca posicionar a la arqueología contextual como una disciplina científica (contra las críticas de la arqueología procesual), no define claramente su posición. Mantiene siempre un dejo de "cientificismo" propio de las ciencias naturales, que funciona como garantía de legitimación de la nueva corriente.

\section{La "simetrización" de la arqueología: Hodder y el "enredo" entre personas y cosas}

Uno de los últimos trabajos de Hodder (2012) trata sobre las relaciones entre las personas y las cosas en términos de simetría. La arqueología simétrica es una corriente que surgió en los últimos años y que propone volver a la "cruda materialidad" de las cosas (Alberti et al. 2001; González Ruibal 2007; Olsen 2007, 2013, entre otros). Esta postura, que se pretende una superación del "giro social" producido por la arqueología hermenéutica, es básicamente anti-representacional ya que propone tomar a las cosas por sí mismas sin considerarlas signos de algo más. Sin embargo, la postura propuesta por Hodder es un poco más moderada que los demás autores alineados en esta tendencia.

A continuación, voy a desarrollarla brevemente para luego considerar su relación con la posición hermenéutica inicial. Mi anticipación de sentido al respecto es que la arqueología simétrica busca un "ocultamiento del intérprete" que no es posible lograr, incurriendo de esta manera en una serie de contradicciones. Primero, ya la producción de textos científicos sobre las cosas es una 
forma de representarlas. Por lo tanto, una postura antirepresentacional coherente no debería ni siquiera hablar sobre las cosas. Segundo, la propuesta positiva de estos autores, que es volver a las características "materiales" en el sentido más estricto (propiedades físicas y químicas), también es una forma de representación, y particularmente una relacionada con una visión científica de las cosas. Los procesos físicos y químicos son una construcción científica occidental que se encuentra muy lejos de una postura simétrica. Lo peligroso es que estos presupuestos no se encuentran explicitados, lo cual produce consecuencias éticas más peligrosas aún. Más adelante retomo esto.

Volviendo a Hodder (2012), su última propuesta tiene que ver con el "enredo" entre las personas y las cosas. El enredo es definido como la sumatoria de las relaciones entre los humanos y las cosas, las cosas con las cosas, las cosas con los humanos y los humanos con los humanos. Existe una doble relación entre los humanos y las cosas: por un lado, dependen de cosas, y por el otro, las cosas dependen de los humanos. Esto implica que las cosas tienen una habilidad limitada para reproducirse, por lo que en nuestra dependencia de ellas nos encontramos atrapados en la dependencia de ellas con nosotros. Hay una dialéctica entre dos tipos de dependencia, intraducible al español: dependence, como productiva y habilitadora, $y$ dependency, como limitante y constreñidora. En función de esta distinción, el enredo es caracterizado por Hodder como la dialéctica entre la dependence y la dependency.

El mundo de las cosas, que en principio se encuentra separado del mundo social, ejerce una atracción sobre los humanos, por lo que se produce un enredo entre ambos. Este enredo se produce a través del flujo de materia, energía e información que atraviesa a las cosas. Para abordar esta relación en la arqueología, Hodder propone focalizarse en los procesos físicos de las cosas que las enredan con los humanos. El desgaste, por ejemplo, hace necesario el cuidado de las cosas. En este sentido, también hay una dialéctica entre las temporalidades de los humanos y de las cosas. Al ser más duraderas, las últimas sirven para fijar las relaciones entre humanos. El enredo funciona a diferentes escalas, es más fácil de reconocer a escala local pero tiene consecuencias y nexos abiertos. También es importante destacar que las relaciones que produce son contingentes.

\section{* Tercera parte: Arqueología y HERMENÉUTICA}

De acuerdo con lo expuesto supra, podemos identificar dos momentos en las relaciones entre la arqueología y la hermenéutica, que se relacionan a su vez con los diferentes horizontes de sentido en los cuales se encuentran insertos. El primero de ellos se relaciona con el surgimiento de la arqueología hermenéutica y su posicionamiento dentro del campo de la arqueología. El segundo, con una supuesta superación de las primeras posturas y un acercamiento entre las personas y las cosas. Vamos a desarrollarlos a continuación.

\section{Arqueología y hermenéutica en el surgimiento de la arqueología contextual}

La hermenéutica filosófica cumplió un rol fundamental en la justificación teórico metodológica de la arqueología contextual. En contra de la arqueología procesual de corte positivista, fue necesario localizar otras fuentes de apoyo para la nueva propuesta. Uno de los elementos del positivismo que critica Hodder (1986) y otros (por ejemplo, Shanks y Tilley 1987) es la "supresión" del intérprete en favor de una supuesta "objetividad" de la arqueología. Para solucionar este problema, la propuesta es que la arqueología es una ciencia interpretativa. Esto lleva directamente a la consideración de la hermenéutica filosófica como posible metodología. Sin embargo, y sobre todo a mediados de los 80, este movimiento implicó considerar a la cultura material de manera análoga a un texto. A partir del comentario a Reading the past en su primera edición, vimos que Hodder (1986) se muestra bastante ambiguo en la relación entre interpretación, texto y cultura material. La cultura material es como un texto, pero con diferencias. También es problemático el énfasis en la interpretación de los símbolos sociales, a partir de la abstracción de los significados contextuales.

Estas tensiones se aligeran en el segundo trabajo comentado, que versa específicamente sobre la aplicación de la hermenéutica, en particular las nociones de horizonte, fusión de horizontes y círculo hermenéutico. Aquí Hodder (1991) se acerca más aún a la hermenéutica filosófica, sobre todo a la propuesta de Gadamer comentada más arriba. Sin embargo, vemos también que hay una nueva tensión entre la objetividad y la subjetividad de las 
interpretaciones. Hodder sostiene que los arqueólogos deben retener cierta "autoridad" sobre las interpretaciones, lo cual se contradice con la voluntad de "multivocalidad" de la arqueología. Para superar esta contradicción, solamente es necesario recurrir al concepto de historia efectual de Gadamer y reconocer que no existen interpretaciones objetivas, ya que el intérprete es efecto de la tradición que pretende interpretar. Pero este movimiento sería demasiado radical para ser aceptado por la crítica, en un momento donde la arqueología contextual se encontraba peleando por ser legitimada en la academia. En consecuencia, vemos un uso selectivo de los conceptos de la hermenéutica filosófica debido a una situación hermenéutica particular, que se enfrenta con una tradición dentro de un campo académico para aumentar el capital simbólico (Bourdieu 2003; Vaquer 2013a).

\section{Entangled y el colvido? de la hermenéutica}

Siguiendo el análisis en términos de campo, en Entangled (Hodder 2012) ya no existe esta lucha por el posicionamiento, ya que el autor posee suficiente capital simbólico como referente teórico. El objetivo, esta vez, es acercarse a las posturas simétricas postulando una versión más leve de la simetría entre las personas y las cosas. Esto implica una serie de alejamientos de las posturas hermenéuticas anteriores, ya que la simetría, en la versión de Hodder, es un intento de "nivelar" la agencia entre las personas y las cosas.

El primer distanciamiento se produce a partir de correr el foco de atención desde los sistemas simbólicos, y sus realizaciones en la práctica, hacia el enredo entre las personas y las cosas. En este nuevo escenario, no caben de manera explícita las herramientas interpretativas de la hermenéutica, ya que el intérprete no cumple un rol (aparentemente) en las interpretaciones. Sin embargo, el intérprete sigue estando de manera velada. Nos presenta un nuevo tipo de intérprete, un nuevo tipo de agente disperso, que hace lo posible por ocultarse y diluirse entre los procesos físicos de las cosas, la temporalidad y las relaciones. Si bien es aceptable la relación de dependencia entre las personas y las cosas, y entre las cosas y las personas, los agentes que ponen en valor tales relaciones y las señalan son las personas, no las cosas. Por más que aboguemos por una simetría extrema, siempre los que abogamos somos nosotros, no las cosas. Las cosas habilitan y constriñen (sería imposible haber escrito este trabajo sin cosas, solamente con ideas), pero es necesaria la presencia de las personas para ser habilitadas y constreñidas. En consecuencia, la simetría es una ilusión, un juego retórico que, por el mismo hecho de serlo, se anula.

Desde una postura crítica, todo discurso simétrico es una contradicción performativa. Dejemos hablar a las cosas; entonces no deberíamos escribir trabajos en su defensa. Ya la mera argumentación en favor de las cosas, la "defensa de las cosas" (Olsen 2013) es situarlas en un universo de representación. Así, no existen las cosas, al menos desde una perspectiva académica ${ }^{3}$, sin representación. La simetría se anula...

Si bien el objetivo específico de este trabajo no es hacer una crítica a las posturas simétricas, o "nuevo materialismo" según Whitmore (2014), es necesario mencionar algunas que se relacionan en particular con la propuesta de Hodder revisada. Según Whitmore, el "nuevo materialismo" es el resultado de una serie de "giros" que se produjeron durante la década del 90: el giro ontológico, el giro de la agencia, el giro de las especies y el giro o retorno a las cosas. Este movimiento se basa en tres proposiciones generales, que según el autor son una más radical que la otra. La primera de ellas es que las cosas con conjuntos (assemblages), la segunda que las cosas son participantes, y la tercera que las cosas son cosas. Con respecto a la primera proposición, implica dejar de lado la oposición entre objetos inanimados separados de los sujetos humanos con intencionalidad como un producto indeseado de la modernidad (véase González Ruibal 2007). Que las cosas sean conjuntos implica que no es posible diferenciar entre los sujetos y los objetos, entre la naturaleza y la cultura, ya que las mismas son más o menos la suma de sus partes, el conjunto de varias entidades que no deben diferenciarse a priori. La segunda proposi-

3 Distinto sería si se pretendiera caracterizar la relación entre las personas y las cosas desde la perspectiva de la praxis cotidiana, no científica. En este ámbito "originario" (sensu Heidegger 2012) no existe una separación entre las personas y las cosas, la relación es práctica y no tematizada. Pero siempre que se inserta esta relación en un discurso académico, existe una objetivación y separación entre sujeto y objeto. Las categorías que utiliza Heidegger son lo "a la mano" y lo "ante los ojos" para mostrar la diferencia entre la práctica y la objetivación. 
ción sostiene que se debe partir desde una ontología "plana" donde la agencia no se encuentre monopolizada por parte de los sujetos, sino que se reconozca que las cosas son capaces de actuar sobre otras entidades. Para ello, hay que tomar una postura "agnóstica" que no distribuya la agencia a priori, sino permitir que las cosas se definan a sí mismas. La tecera proposición implica que las cosas no se agotan en sus relaciones, sino que son irreductibles. Con respecto al tema del rol de las personas, Whitmore propone que:

"Para la Arqueología Simétrica fue, y sigue siendo, un proceso de recomposición - no debemos olvidar que la misma noción de lo que implica ser humano, ser una cosa, también cambió. [...] Los humanos somos ahora, y siempre fuimos, participantes entre otros. Se sigue que este proyecto involucra más que sostener que la acción, la memoria, la interpretación, la subjetividad o la percepción no son más el dominio exclusivo de los seres humanos; en algún nivel uno puede proponer que nunca lo fueron" (2014: 217-18).

Vemos, entonces, que la propuesta concreta de este movimiento no es asumir que la agencia humana posee una explicación causal a priori en la conformación de los assemblages, sino permitir que las relaciones se presenten por sí mismas. Existen varias críticas posibles, algunas de las cuales las realiza el propio Hodder. En el comentario al trabajo de Whitmore citado supra, Hodder sostiene que el foco en la simetría es complicado moralmente, ya que la idea de una red encubre las diferencias sociales. La mirada "ingenua" que proponen Whitmore (2014) y Olsen (2010) no lo es tanto, o lo es demasiado. Lazzari, comentando el mismo artículo, también apunta hacia las consecuencias políticas de los nuevos materialismos, sobre todo a señalar que asumir una postura simétrica es una postura a la política.

Otro punto posible de crítica que se relaciona con los objetivos de este trabajo es que en su conjunto, las tres proposiciones del nuevo materialismo permiten "pensar en una arqueología sin el Pasado, es decir, sin un ámbito separado donde las vidas fueron vividas, a las cuáles accedemos a través de sus restos materiales que guía nuestros esfuerzos" (Whitmore 2014: 204). Aquí vemos otra postura ingenua. Si bien estoy de acuerdo con que el pasado no es algo objetivo ni separado del presente, el pasado es necesario para que el presente sea el resul- tado del mismo, y de esta manera adoptar una postura crítica. Para la hermenéutica no existe un pasado, sino varios, dependiendo de los intereses de los intérpretes. A partir de dichos intereses es que el pasado surge como una construcción política e ideológica. Si se le niega esta posibilidad al pasado, las cosas y las personas surgen desde un vacío ontológico previo, y las genealogías presentes no son asumidas como resultado de las pasadas.

En síntesis, más allá de los esfuerzos del nuevo materialismo por lograr una simetría total entre las personas y las cosas (situación que el mismo Whitmore reconoce como no posible), es imposible dejar de lado la agencia humana sin caer en una postura políticamente ingenua. La pregunta que surge es ¿cuál es el lugar en la academia que ocupan los adeptos a los nuevos materialismos?, ¿cuál es su situación hermenéutica particular con los intereses concomitantes que llevan a luchar por esta postura con consecuencias políticas no deseables? Considero, al igual que propuse en otro trabajo (Vaquer 2013b), que tanto la arqueología hermenéutica británica como los nuevos materialismos no se enfocan en las consecuencias políticas de sus interpretaciones porque, a diferencia de los contextos de práctica disciplinaria en los que nos desenvolvemos los arqueólogos sudamericanos, no tienen un "otro" que impugne sus interpretaciones. Sobre este punto vuelvo más adelante.

Retornando a la crítica de la propuesta de Hodder, un segundo distanciamiento, relacionado con el primero, es la posición del intérprete, la situación hermenéutica como lugar definido por los intereses y efectuado por la tradición. Si el enredo es contingente, entonces iquién determina las relaciones significativas? Nuevamente tenemos un ocultamiento del intérprete. Seleccionar las variables significativas - no importa cuales sean en particular- dentro de las múltiples interacciones entre las cosas y las personas es tarea del intérprete, y, según la tradición hermenéutica, esta tarea depende de la situación hermenéutica de cada uno con sus intereses concomitantes. Lo mismo ocurre con la escala del enredo: los límites son arbitrarios y abiertos, en consecuencia, tienen que ser puestos por un intérprete. Enfatizar los procesos fisicoquímicos de desgaste no es una manera de nivelar la agencia entre las personas y las cosas, es tomar las cosas desde una perspectiva concreta que las sitúa en un universo representativo particular. 
A modo de síntesis, vimos entonces que desde un primer acercamiento entre arqueología y hermenéutica, siguiendo la estructura del campo académico, Hodder se aleja aparentemente de sus primeros trabajos y produce un ocultamiento del intérprete, lo que deshabilita las herramientas hermenéuticas que se centran en la interpretación. Sin embargo, el intérprete sigue estando presente. A continuación, voy a profundizar en este nuevo tipo de intérprete y las consecuencias prácticas de las interpretaciones. Mi argumento es que, lejos de ser descartada, la hermenéutica es una corriente que permite evaluar la incidencia práctica de las interpretaciones y reconocer los intereses detrás de las situaciones hermenéuticas particulares. En consecuencia, es un paso necesario para la construcción de una arqueología dialógica.

\section{* Conclusiones: Arqueología hermenéutica Y PRAXIS ARQUEOLÓGICA EN AMÉRICA LATINA}

"Así pues, para lograr una perfecta claridad en nuestros pensamientos sobre un objeto, sólo necesitamos considerar qué efectos concebibles de índole práctica podría entrañar ese objeto" (James 2007: 80).

La "máxima pragmática", expuesta aquí por James pero retomada de Peirce, permite evaluar el criterio de verdad de los argumentos a partir de las consecuencias prácticas de los mismos. Ahora bien, ¿qué se entiende por consecuencias prácticas? Considero que las consecuencias prácticas de los argumentos y teorías arqueológicas, y sobre todo de las interpretaciones, son los efectos que las mismas tienen en el presente para los agentes sociales involucrados. Parto de la premisa que la arqueología es un discurso, una narrativa sobre el pasado que construye relaciones de poder (Shanks y Tilley 1987). En tanto, narrativa es el producto de la interpretación, lo cual nos lleva nuevamente a la hermenéutica. En este apartado, argumento a favor de la aplicación de la hermenéutica como herramienta para lograr una arqueología crítica y responsable de sus interpretaciones, a la vez que incluya también las interpretaciones de los demás agentes sociales. Por lo tanto, la hermenéutica es una corriente teórica útil para interpretar el pasado, porque sus resultados permiten constituir una arqueología dialógica que se focalice en los intereses detrás de las interpretaciones del pasado.

En los apartados anteriores, además de caracterizar bre- vemente a la tradición hermenéutica, discutí cómo la misma fue aplicada en arqueología a partir de los trabajos de Hodder. Una de las puertas que abrió la arqueología hermenéutica fue la posibilidad de considerar a la arqueología como un discurso crítico acerca de las construcciones del pasado y sus efectos en el presente. Este elemento crítico se encuentra en los trabajos de Hodder comentados, sin embargo desaparecen en su enredo. En una primera instancia, voy a realizar una crítica de esta última postura a partir de las consecuencias prácticas de las interpretaciones. Si bien las críticas se aplican al trabajo de Hodder en particular, también pueden ser extendidas a la arqueología simétrica en general.

Uno de los primeros puntos a criticar es la posición del intérprete. En sus primeros trabajos, Hodder reconoce la importancia de situar a las interpretaciones, aunque se manifiesta en contra de una postura subjetivista radical al intentar preservar cierta objetividad dentro de las mismas. Pasa algo similar con el enredo: si bien aboga por la simetría y las conexiones entre las personas y las cosas, el lugar del intérprete permanece ambiguo. Como mencioné anteriormente, el lugar del intérprete se constituye como una agencia repartida entre las diferentes conexiones. Al ser las conexiones contingentes y dependientes de la escala, la identificación de las mismas depende siempre de un intérprete que las limite. Por lo tanto, el intérprete sigue siendo un componente principal de las interpretaciones.

Con respecto a las consecuencias prácticas de esta noción de agencia, al ocultar al intérprete en las conexiones, no existe un lugar de enunciación claro que se responsabilice por las interpretaciones. Si bien los límites de las interpretaciones son formulados por un intérprete determinado — sería imposible de otra manera-, este se "diluye" entre las diferentes conexiones, es ocultado y los efectos de su agencia disminuidos, al menos explícitamente. Este movimiento es peligroso, ya que con el ocultamiento del intérprete se produce un ocultamiento de la situación hermenéutica, de los prejuicios y sobre todo de los intereses que los motivan. En consecuencia, las interpretaciones generadas desde este marco aparentemente serían "inocentes", lo cual no es posible en la práctica. Este marco no permite un reconocimiento del lugar desde donde se producen las diferentes interpretaciones. En el caso del nuevo materialismo, directamente se anula la 
posición del intérprete al negarles toda agencia a priori a las personas.

Diferente es el caso de los primeros trabajos de Hodder. Si bien no reconoce que la situación hermenéutica es efecto de la tradición que está siendo comprendida y, en consecuencia, no es posible la objetividad de las interpretaciones, al aplicar las herramientas de la hermenéutica construye un lugar de enunciación fuerte. Demasiado fuerte tal vez, ya que al negar la efectuación de la historia en la situación hermenéutica, sostiene una pretensión de objetividad que le da al enunciador un poder diferencial sobre las interpretaciones del pasado. El arqueólogo/a tiene un derecho, una autoridad sobre las interpretaciones, y su deber ético es compartir una parte de ese poder con las sociedades o los grupos subalternos. En consecuencia:

"La interpretación es traducción. Involucra al arqueólogo actuando como un intérprete entre el pasado y el presente, entre diferentes perspectivas del pasado, y entre lo específico y lo general. La interpretación involucra, por lo tanto, escuchar, entender y acomodar diferentes voces en vez de solamente la aplicación de instrumentos universales de medida [...] El rol de la Arqueología Interpretativa es facilitar la inclusión del pasado en un presente multicultural" (Hodder 1991: 15).

La multiculturalidad como postura epistémica fue criticada acertadamente por Gnecco (2009). El multiculturalismo es para este autor una retórica esencialista que supone y promueve las diferencias culturales, reconfigurando las relaciones sociales y las formas de identidad. Su política se basa en el conocimiento y la delimitación de la diferencia cultural pero que, en última instancia, no logra un diálogo ni una relación entre las identidades culturales que define esencialmente. El resultado es un monopolio narrativo de la lógica científica sobre las lógicas locales, lo cual continúa la violencia epistémica colonialista que construye e impone su propia lógica al pasado para justificar un presente de dominación. En consecuencia, la postura hermenéutica inicial de Hodder tampoco tiene consecuencias prácticas deseables.

Si situamos nuestra práctica arqueológica en un contexto latinoamericano, donde nuestras interpretaciones repercuten en un "otro" presente (distinto es el caso de Europa, véase Vaquer 2013b), entonces debemos adecuar nuestros marcos a los intereses del otro. El problema del "otro" y el "mismo" fue tratado por varios filósofos, entre ellos Emanuel Lévinas (2002). Este autor propone que para evita totalizar al "otro", es decir, subsumirlo bajo los esquemas interpretativos del "mismo", es necesario considerarlo como infinita y radicalmente distinto. Esta separación absoluta, que impide la totalización del "otro", es comparada por Lévinas con la "idea de infinito" propuesta por Descartes en la Tercera meditación para probar la existencia de Dios. Ahora bien, una vez establecida la separación radical, la manera de relacionarse con esta exterioridad, que es el "otro", es necesariamente el diálogo. El diálogo respeta la trascendencia del "otro" en tanto implica una interacción cara a cara y la presencia en lugar de la representación o el concepto.

Ya destacamos la voluntad dialógica de la hermenéutica desde sus orígenes. Para lograr establecer un diálogo con el "otro" que no resulte en la imposición de esquemas conceptuales - dando lugar a una nueva forma de colonialismo-, es importante considerar los intereses en juego en cada una de las interpretaciones a partir de explicitar las situaciones hermenéuticas de los involucrados en el diálogo.

\section{Hermenéutica y práctica arqueológica en Sudamé- rica: por una arqueología (a)simétrica}

El énfasis en la situación hermenéutica nos lleva a situar nuestra práctica arqueológica y las herramientas teórico metodológicas que usamos en su contexto de producción y aplicación. Como mencioné al comienzo de este trabajo, considero que es uno de los pasos necesarios para lograr una arqueología crítica que posea valor social. Con respecto a la postura sostenida en este trabajo, no existen antecedentes regionales publicados que aborden esta problemática. Son excepciones los trabajos de Carbonelli (2011) y Acosta (2013), aunque el objetivo de estos autores es hacer un recorrido por las principales tendencias teóricas de la arqueología, no elaborar un marco específicamente hermenéutico.

La relación entre praxis arqueológica y situación hermenéutica no es la misma para los investigadores (en general y europeos) que para los latinoamericanos. Por lo tanto, las arqueologías de unos y otros deben ser diferentes. Salerno (2012), desde el marco de la arqueología 
pública, propone un excelente análisis situado de la práctica arqueológica en Sudamérica. Uno de sus puntos más importantes es que, ya desde sus inicios, la arqueología latinoamericana fue el producto de una situación colonial, donde las primeras instituciones e investigadores que consolidaron las narrativas sobre el pasado americano dependían de los centros hegemónicos, en particular de Europa. Esto resultó en una negación de las historias de los pueblos americanos y su inserción en esquemas evolutivos europeos considerados naturales y universales.

Los contextos de práctica arqueológica de América Latina y Europa son radicalmente distintos: el nuestro es el producto de una situación colonial que se intenta revertir, donde "el Otro ya no es exterioridad, sino interioridad constitutiva" (Gnecco 2012, véase Haber 2013). Esta presencia del "otro" es lo que la arqueología europea no enfrenta, ya que sus narrativas tratan sobre un pasado egocéntrico que sirvió como modelo a las narrativas arqueológicas impuestas afuera. Considero que es por esto último que la arqueología simétrica puede darse el lujo de ser ingenua: es el producto de una mirada meramente académica que no se preocupa - porque no lo necesitapor los resultados prácticos de sus interpretaciones y de los supuestos metafísicos que aduce no poseer. Ya por esto debe ser rechazada en el contexto sudamericano: la situación hermenéutica de la que procede es colonialista y busca mantener un statu quo de dominación epistémica, al ignorar que lo que constituye nuestra disciplina no es la simetría, sino la diferencia, una diferencia de poder que al ser ignorada pretende ser reproducida. La asimetría más importante no es la que se da entre las personas y las cosas, sino la que existe entre las personas.

En consecuencia, la pregunta por la situación hermenéutica nos lleva a considerar los contextos de enunciación de las teorías, y cómo las mismas son el producto de trayectorias académicas diferentes - una de colonizados y otra de colonizadores - esencialmente (a)simétricas. El lector perspicaz se estará haciendo la siguiente pregunta: ¿Pero la hermenéutica no es también una herramienta metodológica europea científica? Sí. La ciencia, como empresa, siempre fue y será colonialista. No tiene sentido negarlo. Las opciones son dos: o dejar de hacer ciencia y considerar que la arqueología es "otra cosa" o deconstruir los marcos y aplicarlos para que las narrativas que produ- cimos tengan algún valor en las luchas políticas actuales.

\section{Hacia una arqueología hermenéutica crítica}

Una de las posibilidades es descartar el enfoque hermenéutico. Varios autores de orientación marxista (Aguilar Díaz y Tantaleán 2008; McGuire 2008) toman este camino. También son destacables las críticas de Criado Boado (2001, 2006) sobre las relaciones entre las interpretaciones y la subjetividad. Si bien no estoy de acuerdo con este autor respecto de la necesidad de una objetividad en las interpretaciones (que propone lograr a partir de un método interpretativo en dos fases: una enunciación de las interpretaciones y una interpretación de las interpretaciones; véase Criado Boado 2006), es cierto que las interpretaciones necesitan de criterios para ser validadas. Estos criterios de validez son los que nos alejan de la caricatura de la hermenéutica como un "todo vale interpretativo". En otro trabajo (Vaquer 2013a) propuse que las interpretaciones son el producto de la intersección entre tres horizontes o tradiciones: por un lado, la tradición académica, que determina los límites de las posibles interpretaciones en términos de inserción profesional en el campo académico (Bourdieu 2003); por otro lado, un horizonte constituido por las interpretaciones de las comunidades acerca del pasado; finalmente, un horizonte constituido por la cultura material (en particular el paisaje). En consecuencia, si bien no considero posible (ni deseable) evitar la subjetividad de las interpretaciones, las mismas no son el producto solipsista de un investigador o un grupo de investigación aislado, sino que siempre tienen una naturaleza social compartida desde su adscripción a un campo científico determinado y a sus relaciones de poder, tienen una base empírica en la materialidad del paisaje y tienen un monitoreo práctico en la interacción con las comunidades. Es por esto que considero que una aplicación de la hermenéutica con sus componentes principales permite avanzar hacia una arqueología crítica y socialmente comprometida, y no se trata de un mero juego subjetivista.

Vamos a comenzar por las herramientas teórico metodológicas. El concepto de situación hermenéutica, tanto desde su estructura triple del Vor como de la conciencia de la historia efectual, permite dar cuenta de los intereses que subyacen a toda interpretación. Esto es aplicable tanto a las situaciones hermenéuticas de los investigado- 
res como de los vecinos y pobladores que se relacionan cotidianamente con la cultura material. El primer paso para construir una arqueología dialógica es explicitar los intereses de cada una de las partes involucradas.

El concepto de horizonte o tradición también resulta rentable en varios niveles. El objetivo de la hermenéutica filosófica es lograr una fusión entre el horizonte del intérprete y el horizonte interpretado (Gadamer 2003). Esta fusión de horizontes se logra a partir de realizarle preguntas a la tradición a partir de intereses presentes. En el caso de la arqueología, tenemos al menos tres horizontes: el pasado a interpretar, el horizonte de las comunidades y el de los investigadores. El horizonte en tanto trasfondo sobre el cual se recorta el "objeto arqueológico" es diferente para cada uno de los agentes involucrados. En el caso de los investigadores, ese trasfondo depende de la historia de vida y la formación académica; mientras que para las comunidades es el horizonte de la vida cotidiana. En consecuencia, existen modos de darse diferente del "objeto arqueológico" según las situaciones hermenéuticas particulares ${ }^{4}$. Esas condiciones del darse diferenciales son la base para un análisis fenomenológico de la constitución del "objeto arqueológico" en cada caso, y un primer paso en la construcción de un diálogo entre ellas.

Por lo tanto, las herramientas de la hermenéutica permiten caracterizar las situaciones hermenéuticas particulares y, a partir de ello, avanzar en un diálogo que tome en cuentas las diferentes epistemes involucradas en las interpretaciones del pasado. Otro de los elementos de la hermenéutica es la voluntad dialógica y dialéctica entre el pasado y el presente. En nuestro caso particular, este diálogo también involucra el horizonte de las comunidades. El diálogo sería entonces entre los investigadores y sus representaciones del pasado, y las comunidades y sus representaciones. El objetivo no es sintetizar o fusionar ambas lógicas u horizontes (aquí me separo de la pro- puesta de Gadamer), sino construir interpretaciones que incluyan ambas lógicas.

Subyace a esta discusión una problemática más profunda. ¿Quién posee las credenciales para interpretar el pasado? ¿Cuál es el valor de verdad de cada una de las interpretaciones? Si bien la idea de un diálogo interepistémico suena bastante utópica, la pregunta por la validez de las interpretaciones y el valor de verdad es un primer paso en esa dirección. La violencia epistémica no puede ser erradicada, pero sí mitigada y deconstruida.

A modo de conclusión, y volviendo a la "máxima pragmática" citada más arriba, podemos ver que la hermenéutica posee consecuencias prácticas deseables para la constitución de una arqueología relacional crítica que busque mitigar los efectos de la violencia epistémica, incluyendo las lógicas de las comunidades en las interpretaciones. Esto implica situar a la arqueología en la tradición de las "ciencias del espíritu", basadas en el comprender como herramienta principal. Si bien no existen recetas y cada caso particular implica desafíos propios, espero que la propuesta volcada en este trabajo sirva para reflexionar y centrarse en las consecuencias prácticas de las interpretaciones.

Agradecimientos Este trabajo fue el producto de una invitación de la cátedra "Teorías Arqueológicas Contemporáneas" de la carrera de Ciencias Antropológicas, Facultad de Filosofía y Letras, UBA, para dar una clase sobre arqueología hermenéutica. Agradezco a los Doctores Hugo Yacobaccio y Marcelo Morales por la invitación. También quiero hacer extensivo mi agradecimiento al resto de los integrantes de la cátedra y a los alumnos que participaron de la clase. Finalmente, quiero agradecer a los tres evaluadores anónimos, que con sus críticas me hicieron repensar algunos de los puntos del trabajo y contribuyeron a mejorarlo.

4 Este argumento será el tema para un trabajo futuro. 


\section{* Referencias citadas}

ACOSTA, M. 2013. No sabe - no contesta. Se es postprocesualista, interpretativo o fenomenológico: ¿Hay un modelo a seguir? Arqueología 19: 11-31.

AGUILAR DÍAZ, M. y H. TANTALEÁN. 2008. El vuelo de Hermes: una crítica a la posmodernidad en la Arqueología desde los Andes. Maguaré 22: 397-423.

ALBERTI, B., S. FOWLES, M. HOLBRAAD, Y. MARSHALL y C. WITMORE. 2011. Worlds otherwise: Archaeology, Anthropology and Ontological Difference. Current Anthropology 52(6): 896-912.

BINFORD, L. 1988. En busca del pasado. Editorial Crítica, Barcelona.

1996. Willow smoke and dog's tails: hunter - gatherer settlement systems and archaeological site formation. En Contemporary Archaeology in Theory. A reader, R. Preucel e I. Hodder (Eds.), pp. 39-60. Blackwell, Oxford.

BOURDIEU, P. 2003. El oficio del científico. Ciencia de la ciencia y reflexividad. Anagrama, Barcelona.

CARBONELLI, J. P. 2011. La interpretación en Arqueología. Pasos hacia la hermenéutica del registro. Prometeica 5: 5-17.

CRIADO BOADO, F. 2001. Problems, functions and conditions of archaeological knowledge. Journal of Social Archaeology 1(1): 12 6-16.

2006. ¿Se puede evitar la trampa de la subjetividad? Sobre arqueología e interpretación. Complutum 17: 247-253.

GADAMER, H. G. 2003. Verdad y método I. Ediciones Sígueme, Salamanca.

GNECCO, C. 2009. Caminos de la Arqueología: de la violencia epistémica a la relacionalidad. Boletín del Museo Paranaense "Emílio Goeldi" 4(1): 15-26.

2012. Arqueología multicultural. Notas intempestivas. Complutum 23(2): 93-102.

GONZÁLEZ-RUIBAL, A. 2007. Arqueología Simétrica: Un giro teórico sin revolución paradigmática. Complutum 18: 283-319.

GRONDIN, J. 1999. Introducción a la hermenéutica filosófica. Herder, Barcelona.

2008. ¿Qué es la hermenéutica? Herder, Barcelona.
HABER, A. 2013. Arqueología y desarrollo: anatomía de la complicidad. En Arqueología y desarrollo en América del Sur. De la práctica a la teoría, A. Herrera Wassilowsky (Comp.), pp. 13-18. Universidad de los Andes, Bogotá.

HEIDEGGER, M. 2002. Interpretaciones fenomenológicas sobre Aristóteles. Indicación de la situación hermenéutica [Informe Natorp]. Editorial Trotta, Madrid.

2005. La idea de la filosofía y el problema de la concepción del mundo. Herder, Barcelona.

2012. El Sery el tiempo. Fondo de Cultura Económica, México, D. F.

HODDER, I. 1986. Reading the past. Current approaches to interpretation in archaeology. Cambridge University Press, Cambridge.

1991. Interpretive Archaeology and It's Role. American Antiquity 56(1): 7-18

2012. Entangled. An Archaeology of the Relationships between Humans and Things. Willey-Blackwell, Sussex.

JAMES, W. 2007. Pragmatismo. Un nuevo nombre para viejas formas de pensar. Alianza Editorial, Madrid.

JOHNSEN, H. y B. OLSEN. 1992. Hermeneutics and Archaeology: On the Philosophy of Contextual Archaeology. American Antiquity $57(3): 419-436$.

KANT, I. 2009. Crítica de la razón pura. Colihue, Buenos Aires.

LÉVINAS, E. 2002. Totalidad e Infinito. Ensayo sobre la Exterioridad. Ediciones Sígueme, Salamanca.

MCGUIRE, R. 2008. Archaeology as Political Action. University of California Press, Los Angeles.

OLSEN, B. 2007. Genealogías de la asimetría: por qué nos hemos olvidado de las cosas. Complutum 18: 287-291. 2013. In defense of Things. Archaeology and the Ontology of Objects. AltaMira Press, Nueva York.

RICOEUR, P. 2002. Del texto a la acción. Ensayos de Hermenéutica II. Fondo de Cultura Económica, México, D. F.

2003. Teoría de la interpretación. Discurso y excedente de sentido. Siglo XXI Editores, Buenos Aires. 
SALERNO, V. 2012. Pensar la arqueología desde el sur. Complutum 23(2): 191-203.

SCHIFFER, M. B. 1972. Archaeological context and systemic context.American Antiquity 37(2): 156-165.

SHANKS, M. y C. TILLEY. 1987. Social Theory and Archaeology. Blackwell, Oxford.

VAQUER, J. M. 2013a. La Tradición como Límite de la Interpreta- ción. Un ejemplo desde Cruz Vinto (Norte de Lípez, Bolivia). Relaciones de la Sociedad Argentina de Antropología XXXVIII(2): 269-291.

2013b. Las aporías de la Arqueología Hermenéutica. En busca de un nuevo criterio de validez. Arqueología 19: 151172 .

WHITMORE, C. 2014. Archaeology and the New Materialisms. Journal of Contemporary Archaeology 1-2: 203-246. 